\title{
Shielding Effect of High Frequency Power Transformers for DC/DC Converters used in Solar PV Systems
}

\author{
Sascha Stegen $^{\# 1}$, Junwei $\mathrm{Lu}^{\# 2}$ \\ ${ }^{*}$ Griffith School of Engineering, Griffith University, Nathan, Brisbane Qld 4111, Australia \\ ${ }^{1}$ Sascha.Stegen@student.griffith.edu.au \\ ${ }^{2}$ J.Lu@griffith.edu.au
}

\begin{abstract}
Conventional high frequency power transformers are configured without protection to avoid parasitic effects. Therefore this paper presents and investigates a FEM technique and measurement results for planar and coaxial high frequency power transformers used for DC/DC converters in photo voltaic (PV) power systems. The winding structure includes a Faraday shield between the primary and secondary windings and is designed to minimize skin and proximity effects, eddy current losses, the leakage inductance, and the inter winding coupling capacitance. Finite Element Method is employed to analyze the magnetic flux and eddy current distributions, and to accurately calculate the intra- and inter- winding capacitances based on the theory of capacitances in a multi-conductor electro-magnetic system. The two different kinds of HF transformers have been tested and experimentally simulated. The measured results demonstrate, in contrast to non shielded transformers, that the shielded transformers have achieved the expected results with a relatively small coupling capacitance, compared with the conventional high frequency transformer. This shield decreases the inter-winding coupling capacitance $\mathrm{Cps}$ and the leakage induction.
\end{abstract}

\section{INTRODUCTION}

Inverters with isolation transformers are essential, considering the safety and reliability of solar photovoltaic (PV) installations. As shown in Fig. 1, a method to avoid the use of one large transformer is to make use of the higher output power from multiple solar PV modules, achieved by connecting each PV array to its own DC/DC converter and single phase transformer, where the $\mathrm{HF} \mathrm{DC} / \mathrm{AC}$ converter output voltages are phase-shifted to each other by $120^{\circ}$. The secondaries of the HF link transformers are connected in a three-phase configuration, the output windings of the transformer are connected to a three phase rectifier, and the rectifier is connected to an output DC/AC inverter. This configuration concept can be extended to $n$ phases. The $\mathrm{DC} / \mathrm{AC}$ inverter with line frequency output is used to transfer power to the utility and is synchronized to the utility frequency. The power converter architecture connected to the primary terminals of the transformers and the output rectifier can be either current source fed or voltage source fed. Inverters with isolation transformers are essential in many countries considering the safety and reliability of solar PV installations.
A high power, high efficiency, and compact solar PV DC/DC converter has uncovered an enormous amount of physical limitations in regard to eddy currents, heat stability, skin effects, and other parasitic values like unintentional leakage inductance as well as coupling capacitance inside the transformer. A vast number of HF power transformers have been developed for solar PV inverter systems, such as conventional E core or pot core HF transformers, planar core power transformers and coaxial core power transformers $[1,2,3,4]$. The implementation of Faraday shields inside HF transformers can suppress common-mode HF noise that is coupled to the secondary winding [5].

Until now, the shielding effects of winding configurations on the magnetic field distribution, the eddy current distribution in the windings, and power loss inside HF power transformers have not been fully investigated. In high frequency applications, the inter- and intra-winding capacitance can cause serious common-mode HF noise problems because of the coupling of the primary and secondary side [6].

In this paper, high frequency planar and coaxial transformers, with and without Faraday shield, with an operating frequency up to $300 \mathrm{kHz}$, using a FEM based numerical modelling technique and high frequency measurement techniques are investigated. A number of issues related to magnetic flux, current distributions, power losses in windings and the Faraday shield implementation are discussed. Finally, the parasitic capacitances of the model are evaluated using a FEM numerical technique and measurements for the intra- and inter- winding capacitances.

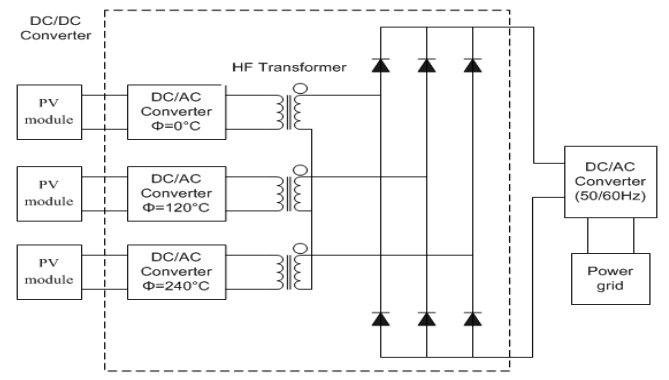

Fig.1. The three phase DC/DC converter for solar PV power conversion systems and its block diagram of PV system. 


\section{StRUCtURAL CONFIGURATION}

The basic structure of the shielded coaxial HF transformer [7] is shown in figure 2. Surrounded by four round ferromagnetic cores, the primary and the secondary winding are connected through the planar layers on the top and bottom (fig.2a). Inside the cores, between the primary and secondary side, the faraday shield implementation is realized through a copper cylinder (fig.2b). It can be seen, that there is a 30 degree offset between the turns. In figure 3 , the structure of the planar transformer is presented. The shielded planar transformer version has a faraday shield copper coated layer between the primary and secondary side.

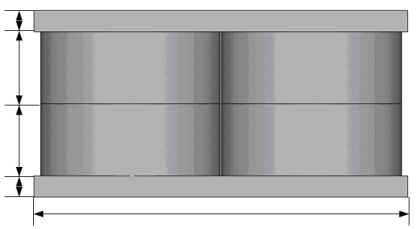

(a)

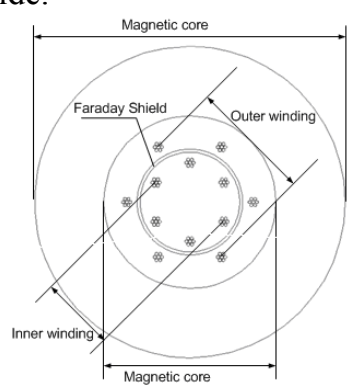

(b)
Fig.2 Configuration of HFCT, (a) side view, (b) half cross-section

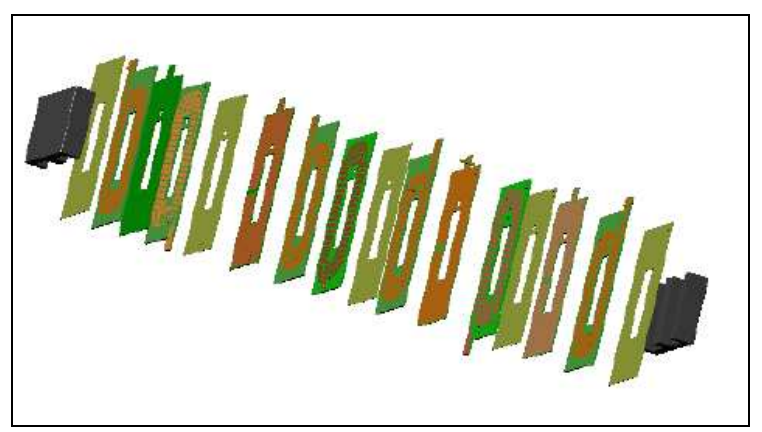

Fig.3 Planar transformer layout.

\section{MAGNETIC FIELD SIMULATION AND ANALYSIS}

\section{A. Eddy Current Calculation}

A Finite Element Method (FEM) based numerical modeling technique was employed to analyze the magnetic field and eddy current distributions for different winding configurations under short circuit and open circuit conditions on the secondary side. The detailed magnetic field properties in the high frequency coaxial transformer (HFCT, fig.4) were then used to facilitate the design of a low loss winding and high efficiency structure.

The mathematical model for this sinusoidal quasi-static eddy current problem is derived from Maxwell equations and is described by the complex magnetic vector potential $\underline{\boldsymbol{A}}$ and an electrical complex scalar potential $\phi$ with Coulomb Gauge

$$
\nabla \times \frac{1}{\mu} \nabla \times \underline{\boldsymbol{A}}-\nabla\left(\frac{1}{\mu} \nabla \cdot \underline{\boldsymbol{A}}\right)+j \omega \sigma(\underline{\boldsymbol{A}}+\nabla \underline{\phi})=\underline{\boldsymbol{J}}_{S}
$$

where $\mu$ is the permeability, $\sigma$ the conductivity, $\omega$ the angular frequency and $\underline{J}_{S}$ the excitation current density.

Figures 4 and 5 visualize that the eddy current, induced from the one winding to the other, is smaller with the inserted Faraday shield. As it can be seen, the current distribution with shielding is higher than without shielding, for the simulation results focusing to the primary winding where the open circuit conditions applied to the coaxial as well as the planar version of HF transformers.

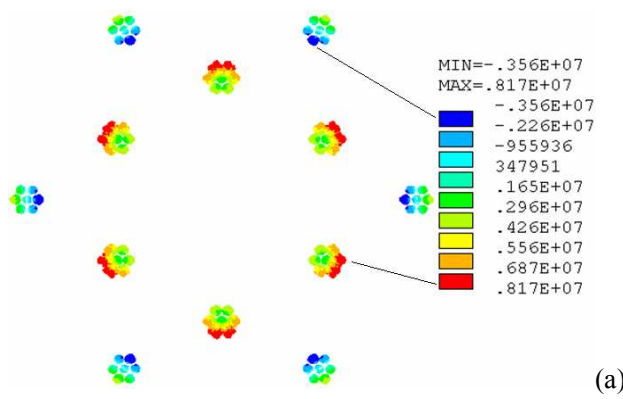

(a)

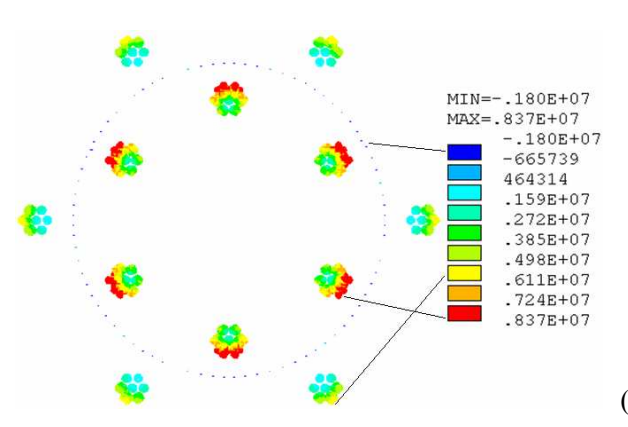

(b)

Fig.4 Current distribution in different winding configurations under open circuit conditions, (a) primary inside without shield and (b) primary inside with shield.

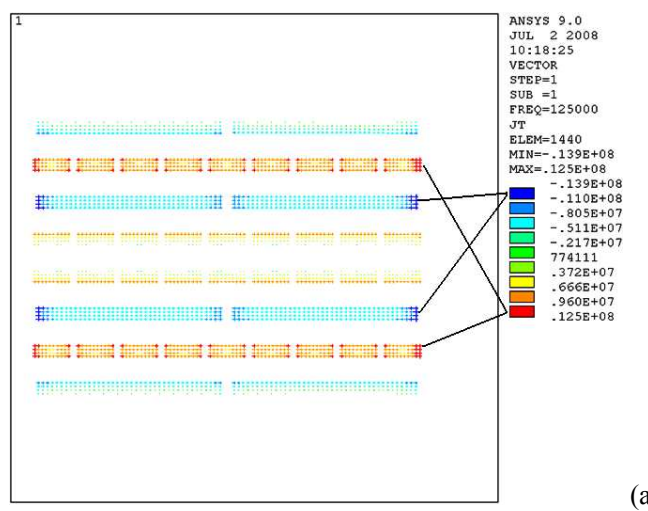




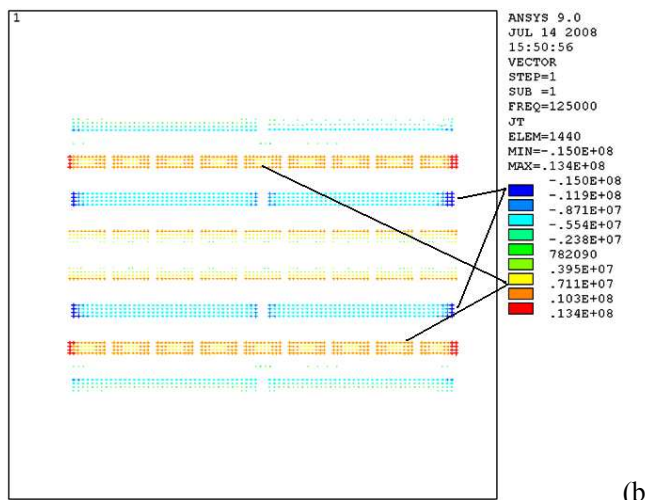

(b)

Fig.5 (a) Eddy current distribution without shielding, (b) Eddy current distribution with shielding

\section{B. Magnetic Flux Distribution}

As shown in the flux quality pictures 6 and 7, the insertion of the Faraday shield does not affect the core flux distribution neither in the coaxial nor in the planar structure.

The field lines are in the same density and allocation, as without the implemented shield.

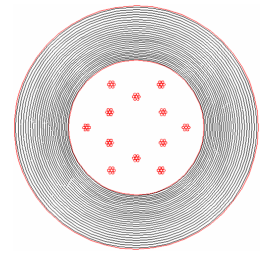

(a)

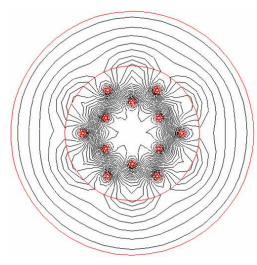

(c)

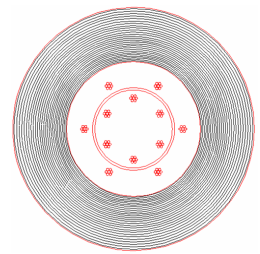

(b)

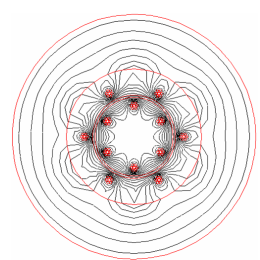

(d)
Fig.6 Flux distribution of the HFCT (High Frequency Coaxial Power Transformer) when the inner winding is used as the primary winding, (a) without shield, under open circuit condition, (b) with shield, under open circuit condition, (c) without shield, under short circuit condition, (d) with shield, under short circuit condition.

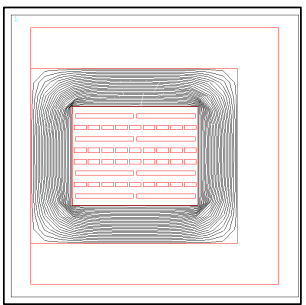

(a)

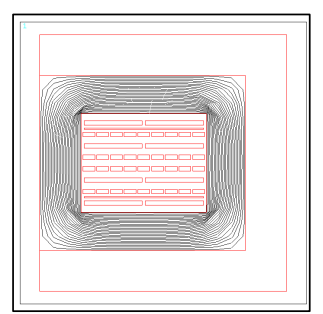

(b)
Fig. 7 (a) Flux distribution without shielding (b) Flux distribution with shielding

\section{MEASUREMENTS OF INTRA- AND INTER- WINDING CAPACITANCES}

\section{A. High Frequency Equivalent Circuit of Transformer}

As apparent from the equivalent circuit diagram of the transformer in figure 8, the unintentional capacitance $\mathrm{Cps}$ is split of to $\mathrm{Cpg}, \mathrm{Cgs}, \mathrm{C}^{\prime}$ ps and $\mathrm{Cs}$. Due to the measurement, the direct measuring of $\mathrm{C}^{\prime} \mathrm{ps}$ is not possible, due to the measurement restrictions.

The capacitance $\mathrm{Cps}$ in figure 8a create coupling and therefore HF impacts between the primary and the secondary winding. After insertion of the faraday shield, the HF noise between the windings is strongly dropped, as it can be seen in figure $8 \mathrm{~b}$, when the shield is connected to the ground.

The HF noise voltage versus propagated to the secondary winding through the coupling capacitance in the no shield case, as shown in Fig. 8(a), is given by:

$$
v_{\mathrm{s}}=v_{\mathrm{p}} C_{\mathrm{ps}} /\left(C_{\mathrm{ps}}+C_{\mathrm{s}}\right)
$$

In the perfectly grounded shield case, HF noise voltage vs. is then given by (as shown in Fig. 7(b), )

$$
v_{s}=v_{\mathrm{p}} C_{\mathrm{ps}}^{\prime} /\left(C_{\mathrm{ps}}^{\prime}+C_{\mathrm{pg}}+C_{\mathrm{s}}\right)
$$

and for the shield in the floating case, HF noise voltage is given by:

$$
v_{s}=\frac{C_{\mathrm{pg}} \cdot C_{\mathrm{gs}}}{\left(C_{\mathrm{gs}}+C_{\mathrm{s}}\right)\left(C_{\mathrm{pg}}+C_{s 0}\right)+C_{\mathrm{gs}} C_{\mathrm{s}}} v_{p}
$$

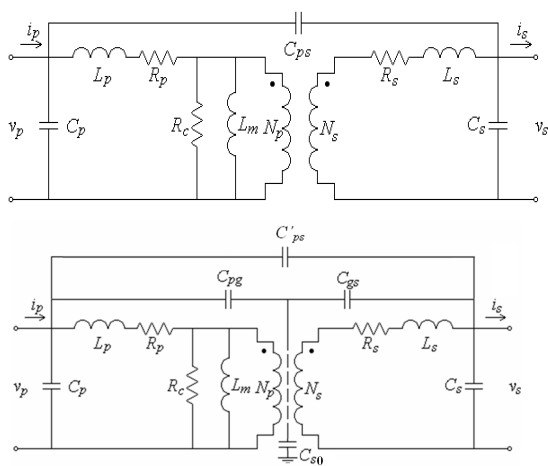

(a)

Fig.8 The HF transformer equivalent circuit, (a) without shield, (b) with shield.

\section{B. Parasitic Capacitance Network}

The fundamental calculations in the FEM technique in this field of application are based on Maxwell's theory. The relation between potential and charge in a multi-conductor system can be described by the electric scalar potential V, which satisfies Poisson's equation,

$$
-\nabla \cdot(\varepsilon \nabla V)=\rho
$$

where $\varepsilon$ is the permittivity, and $\rho$ is the space charge density. Based on the theory of capacitances in multiconductor systems it is possible to get the results for the capacitance network as shown in figure 9 (with implemented Faraday shield (b), without implemented Faraday shield (a)), from the system matrix equation (6). 


$$
\left(\begin{array}{c}
Q_{1} \\
Q_{2} \\
: \\
\vdots \\
Q_{n}
\end{array}\right)=\left(\begin{array}{ccccc}
C_{11} & \cdot & \cdot & \cdot & C_{1 n} \\
\cdot & \cdot & \cdot & \cdot & \cdot \\
\cdot & \cdot & \cdot & \cdot & \cdot \\
\cdot & \cdot & \cdot & \cdot & \cdot \\
C_{n 1} & \cdot & \cdot & \cdot & C_{n n}
\end{array}\right) \bullet\left(\begin{array}{c}
U_{1} \\
U_{2} \\
: \\
: \\
U_{n}
\end{array}\right)
$$

In figure 9 it can be seen, that after inserting the shield, the coupling capacitances are splitting off to smaller capacitances which are directly to the ground. The gap for the capacitances between the primary and secondary windings and the shield is smaller than the gap between the two windings without the shielding. Consequently the value of the coupling capacitance drops down, if the shield is connected to the ground.

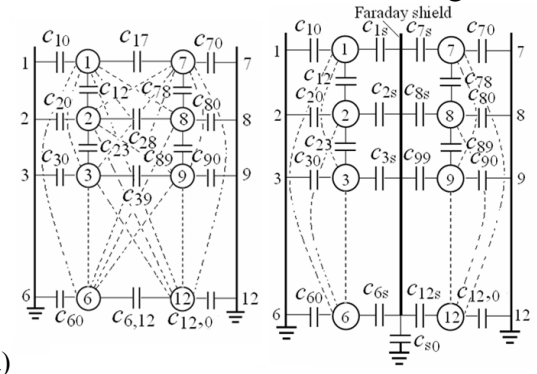

(b)

Fig.9 The parasitic capacitance network model of HF transformer for HF noise analysis, (a) without Faraday shield, (b) with Faraday shield.

\section{Experiment Results}

Figure 10 shows the concept diagram linking the coupling capacitance and leakage inductance, which are dependant from the distance $\mathrm{D}$ between the primary and secondary windings. When measuring the coaxial transformers with inserted Faraday shield, the coupling capacitance between winding and shield increases, but the leakage inductance decreases, in comparison to the non-shielded coaxial version, if the shield is not connected to the ground. The results can be found in table 1 and 2.

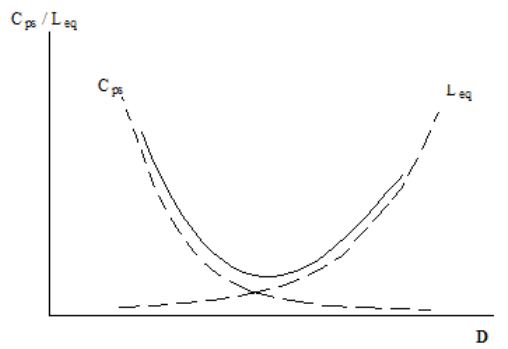

Fig.10 Concept diagram of the relation between the leakage inductance and coupling capacitance, due to the gap distance D between primary and secondary windings

Table 1 and 2 also show the differences between the diverse versions of coaxial and planar transformers. It is obvious that the parasitic capacitance values are declining for the coaxial transformer and the values for the planar transformer are rising.

However, the application of the faraday shield on a planar transformer has its advantage, if the shielding is connected to the ground. As it can be shown in table 2, the parasitic inductance decreased with the shield inside.
After inserting the shield, the capacitance raised due to the fact that the area $\mathrm{A}$ in the basic equation $\mathrm{C}=\varepsilon \mathrm{r} \cdot \varepsilon 0 \cdot(\mathrm{A} / \mathrm{d})$ is higher than without the shield.

These results are corresponding with the graph in figure 10. The measured leakage inductance and coupling capacitance of the HF transformer were obtained by using a HP4285A (75 $\mathrm{KHz}-30 \mathrm{MHz}$ ) precision LCR meter over the frequency range $0.1 \mathrm{MHz}$ to $1 \mathrm{MHz}$. After the shield is connected to the ground, the measured value shrinks to the half. This value is expected to be lower, but the boundary conditions of the measurement device do not allow to measure C'ps and Cs0 directly.

TABLE I

\begin{tabular}{|l|c|c|c|}
\hline \multirow{2}{*}{$\begin{array}{c}\text { Freq. at } \\
\text { 100kHz }\end{array}$} & \multicolumn{3}{|c|}{$\begin{array}{c}\text { Comparison of inter-winding capacitance of HF } \\
\text { transformers with and without shielding }\end{array}$} \\
\cline { 2 - 4 } & $\begin{array}{c}\text { Without } \\
\text { shielding }\end{array}$ & $\begin{array}{c}\text { With shielding } \\
\text { (not grounded) }\end{array}$ & $\begin{array}{c}\text { With shielding } \\
\text { (grounded) }\end{array}$ \\
\hline Coaxial & $32.2 \mathrm{pF}$ & $33.7 \mathrm{pF}$ & $15.5 \mathrm{pF}$ \\
\hline Planar & $615.1 \mathrm{pF}$ & $912.0 \mathrm{pF}$ & $644.0 \mathrm{pF}$ \\
\hline
\end{tabular}

TABLE II

\begin{tabular}{|c|c|c|}
\hline \multicolumn{3}{|c|}{$\begin{array}{c}\text { Comparison of leakage inductance of planar } \\
\text { transformers with and without shielding }\end{array}$} \\
\hline F [kHz] & $\begin{array}{c}\text { Without } \\
\text { shielding }\end{array}$ & $\begin{array}{c}\text { With shielding } \\
\text { (grounded) }\end{array}$ \\
\hline 100 & $9.8 \mu \mathrm{H}$ & $8.3 \mu \mathrm{H}$ \\
\hline 120 & $9.5 \mu \mathrm{H}$ & $8.2 \mu \mathrm{H}$ \\
\hline 150 & $9.4 \mu \mathrm{H}$ & $8.2 \mu \mathrm{H}$ \\
\hline
\end{tabular}

\section{CONCLUSIONS}

Inserting a Faraday shield effectively decreases the interwinding capacitance $\mathrm{Cps}$ and as a consequence of this, significantly reduces the HF impact between the primary and secondary windings. The FEM based simulation and experimental measurements results show and verify that the Faraday shield had no impact on the magnetic coupling coefficient. As the result the power losses on the shield are inconsequential low. As outlined in this paper, inserting the Faraday shield between the secondary and primary windings is an effective way to reduce the unintended parasitic effects.

\section{REFERENCES}

[1] M. H. Kheraluwala, D. W. Novotny, D. M. Divan, "Coaxially Wound Transformers for High-Power High-Frequency Applications," IEEE Trans. On Power Electronics, Vol. 7 No. 1 Jan. 1992, pp 54-62.

[2] K. Yamaguchi and S. Ohnuma, et al., "Characteristics of a thin film microtransformer with circular spiral coils," IEEE Trans. Magn., vol. 29, pp. 2232-2237, Sep. 1993.

[3] J. Lu, F. Dawson, and S. Yamada, "Analysis of high frequency planar sandwich transformers for switching converters," IEEE Trans. Magn., vol. 31, pp. 4235-4237, Nov. 1995.

[4] J. Lu, F. P. Dawson and S. Yamada, "Application and analysis of adjustable profile high frequency switch mode transformer having a Ushaped winding structure", IEEE Trans. on Magnetics, Vol. 34. No. 4, July 1998, pp. 3186-3188.

[5] J. Lu and F. Dasown, "Analysis of Eddy Current Distribution in High Frequency Coaxial Transformer with Faraday Shield," IEEE Trans. On Magnetics, Vol. 42, No. 10, Oct. 2006. pp3171-3173.

[6] X. Yang, J. Lu and F. Dawson, "Optimal Design and analysis of Faraday shield used in high-frequency coaxial transformer," IEEE INTERMAG'2008 Conference, May 2008, Madrid 